\title{
Infected aortic aneurysms presenting with night sweats despite negative blood cultures
}

\author{
Sho Nishiguchi
}

Department of General Internal Medicine, Shonan Kamakura General Hospital, Kamakura, Kanagawa, Japan

\section{Correspondence to} Dr Sho Nishiguchi, sanazen@hotmail.co.jp

Accepted 6 November 2014

\section{DESCRIPTION}

A 76-year-old man, an ex-smoker with hypertension, presented to hospital with a 3-week history of continuous night sweats and low-grade fever. Several days after arrival, he developed upper abdominal pain. Body temperature was $36.9^{\circ} \mathrm{C}$, blood pressure was $140 / 88 \mathrm{~mm} \mathrm{Hg}$ and heart rate was $86 \mathrm{bpm}$. Physical examination revealed upper abdominal tenderness without defence. Laboratory data showed a white cell count of $9600 / \mu \mathrm{L}$ and an elevated C reactive protein of $4.4 \mathrm{mg} / \mathrm{dL}$. A contrast-enhanced CT scan revealed saccular aneurysms with periaortic infiltration in the descending thoracic and abdominal aorta (figure 1). The patient had undergone intravenous antibiotic therapy for suspected bacterial aortitis despite negative blood cultures.
Eighteen days later, CT aortography demonstrated a rapidly enlarging lobulated descending thoracic aneurysm and an abdominal dissecting aortic aneurysm (figures 2 and 3). The patient's condition and inflammatory markers improved during the treatment period. He was discharged 33 days after admission without surgical intervention. He remains stable 4 months after discharge. An aortic stent graft will be performed due to enlargement of both aortic aneurysms.

An infected aortic aneurysm is frequently a fatal disease. A high index of suspicion is required to diagnose infected aortic aneurysms in a patient with a low-grade fever, night sweats and upper abdominal pain and tenderness. Despite negative blood cultures, physicians should consider starting antibiotic treatment as early as possible with the aim to reduce the possibility of aorta rupture.
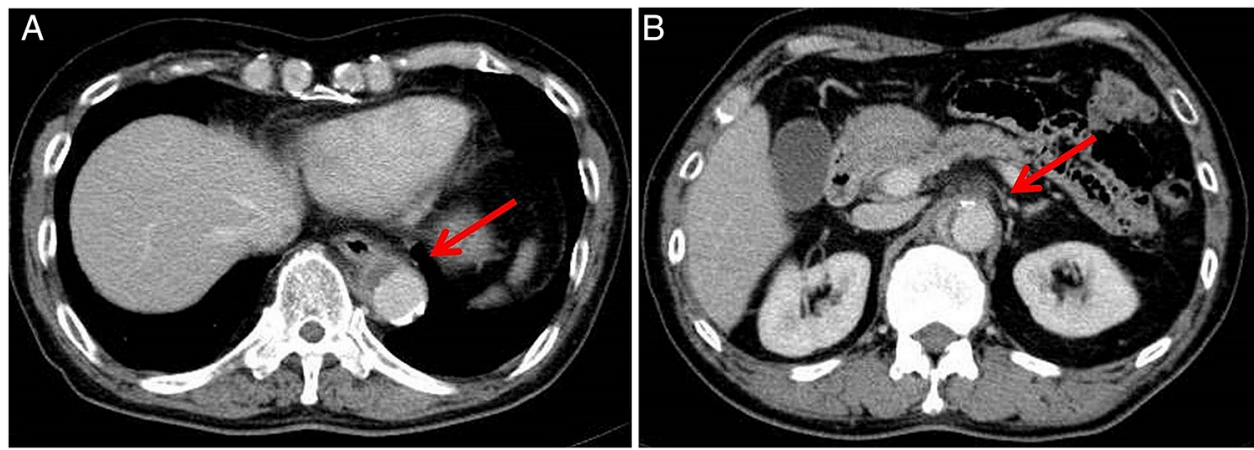

Figure 1 Three days before admission (axial section image). (A) A large saccular aneurysm with a thrombosis and an enhanced aorta wall in the descending thoracic aorta, measuring a maximum diameter of $36 \mathrm{~mm}$ with surrounding inflammation (arrow). (B) A large aneurysm with aorta wall calcification in the descending abdominal aorta, measuring a maximum diameter of $28 \mathrm{~mm}$ with surrounding inflammation (arrow).
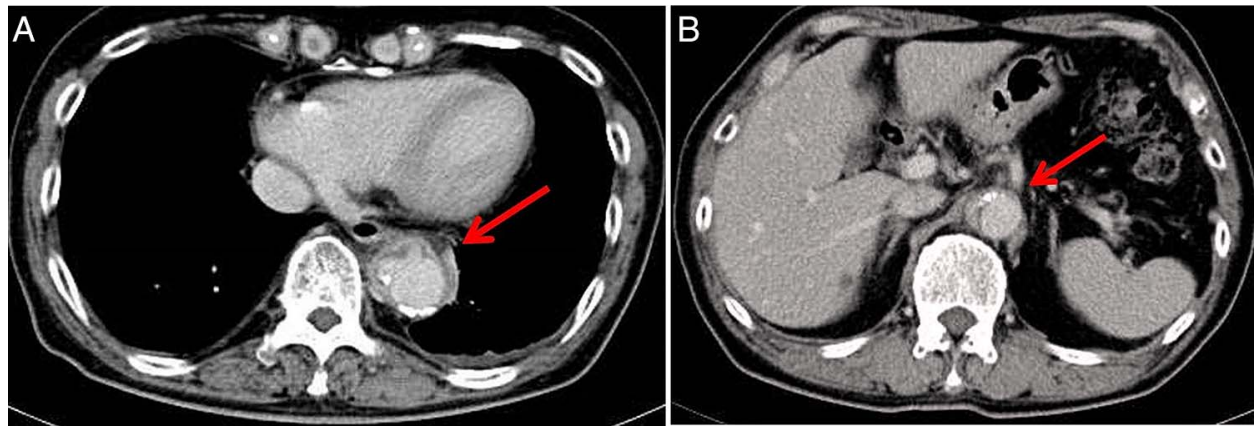

Figure 2 CT aortography 18 days after admission (axial section image). (A) A rapidly enlarging lobulated aneurysm in the descending thoracic aorta measuring a maximum diameter of $38 \mathrm{~mm}$ (arrow). (B) A dissected aneurysm in the abdominal aorta around the coeliac artery enlarged to a maximum diameter of $29 \mathrm{~mm}$ (arrow). 


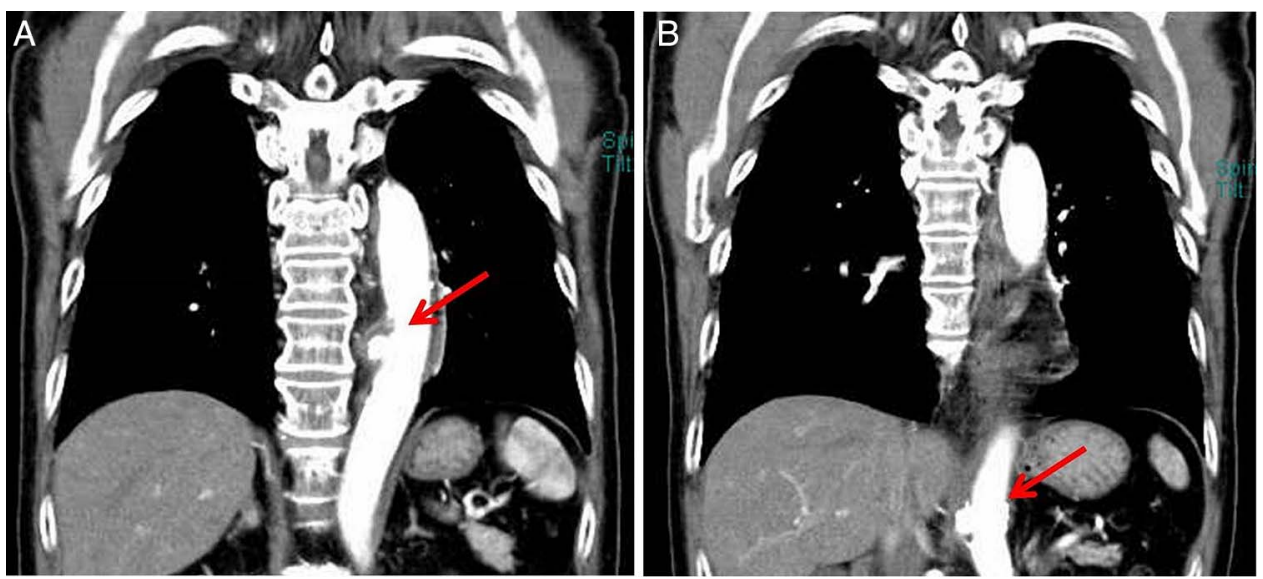

Figure 3 Eighteen days after admission (coronal section image on arterial phase). (A) A rapidly enlarging lobulated aneurysm to the right side of the descending thoracic aorta. (B) Enlargement of a dissection on the right side of the abdominal aorta around the coeliac artery (arrow).

\section{Learning points}

- A contrast-enhanced CT scan should be considered in patients with a low-grade fever, night sweats of unknown cause and upper abdominal pain and tenderness.

- Negative blood cultures cannot rule out an infected aortic aneurysm.
Acknowledgements The author thanks Dr Izumi Kitagawa for his valuable support for this work.

Competing interests None.

Patient consent Obtained.

Provenance and peer review Not commissioned; externally peer reviewed.

Copyright 2014 BMJ Publishing Group. All rights reserved. For permission to reuse any of this content visit http://group.bmj.com/group/rights-licensing/permissions.

BMJ Case Report Fellows may re-use this article for personal use and teaching without any further permission.

Become a Fellow of BMJ Case Reports today and you can:

- Submit as many cases as you like

- Enjoy fast sympathetic peer review and rapid publication of accepted articles

- Access all the published articles

- Re-use any of the published material for personal use and teaching without further permission

For information on Institutional Fellowships contact consortiasales@bmjgroup.com

Visit casereports.bmj.com for more articles like this and to become a Fellow 